\title{
A JUSTIÇA RESTAURATIVA COMO ALTERNATIVA À CULTURA DO ENCARCERAMENTO EM MASSA NO BRASIL ${ }^{1}$
}

THE RESTAURATIVE JUSTICE AS AN ALTERNATIVE TO THE MULTIPLE BORROWING

CULTURE IN BRAZIL

Vitória Gabriella WASQUES ${ }^{2}$

Carlos Henrique GASPAROTO ${ }^{3}$

ISSUE DOI: $10.21207 / 2675-0104.2019 .905$

\section{RESUMO}

A presente pesquisa tem por escopo apresentar a Justiça Restaurativa como alternativa à cultura do encarceramento em massa latente no Brasil, tendo em vista a grave crise do sistema prisional que assola toda a sociedade. Para tanto, faz-se uma análise da atual população carcerária, apontando possíveis causas de referida decadência, bem como um estudo do conceito de justiça restaurativa, tecendo considerações sobre os principais aspectos que envolvem sua aplicação no País. Os métodos utilizados para a abordagem foram o descritivo e o explicativo, uma vez que têm a finalidade de descrever e explicar os fenômenos ligados ao procedimento restaurativo, desenvolvendo-se com base na pesquisa bibliográfica e documental. O conteúdo da presente pesquisa constata que a Justiça Restaurativa é uma alternativa perfeitamente viável ao modelo retributivo atualmente aplicado no Brasil, sendo, inclusive,

${ }^{1} \mathrm{O}$ presente artigo sintetiza a monografia de conclusão da pesquisa realizada para o Programa Interno de Bolsas de Iniciação Cientítica (PIBIC 2018-2019) da Faculdade de Direito de Franca (FDF), Franca/SP.

${ }^{2}$ Discente da Faculdade de Direito de Franca (FDF), Franca/SP. Bolsista do Programa Interno de Bolsas de Iniciação Cientítica (PIBIC 2018-2019). Currículo Lattes: http://lattes.cnpq.br/2554034924794288. Contato: karinagonzaga@hotmail.com.

${ }^{3}$ Promotor de Justiça do Estado de São Paulo, mestre em Direito pela Universidade de Franca (UNIFRAN), professor de Direito Penal I na Faculdade de Direito de Franca (FDF), Franca/SP. Contato: carlos.gasparoto@bol.com.br. 
compatível com o ordenamento jurídico. Alguns estados brasileiros têm utilizado as práticas restaurativas para resolução de conflitos de pequeno e médio potencial ofensivo, apresentando como resultados expressivos desse método o desencarceramento, quando permitido por lei, a maior ressocialização dos indivíduos, diminuindo os casos em que os mesmos voltam a delinquir, bem como a redução da violência, sobretudo dentro dos presídios. A proposta é pensar no futuro e na restauração dos relacionamentos, e não somente concentrar-se no passado, na culpa e em retribuir o mal causado, construindo um corpo social mais justo e humano.

Palavras-chave: Ineficiência do sistema prisional. Cultura do encarceramento. Justiça Restaurativa. Ressocialização. Pacificação social.

\begin{abstract}
The present research aims to present Restorative Justice as an alternative to the culture of latent mass incarceration in Brazil, in view of the serious crisis in the prison system that plagues the entire society. To this end, an analysis of the current prison population is made, pointing out possible causes of said decay, as well as a study of the concept of restorative justice, making considerations about the main aspects that involve its application in the country. The methods used for the approach were the descriptive and the explanatory, since they have the purpose of describing and explaining the phenomena related to the restorative procedure, developing based on bibliographical and documentary research. The content of this research finds that Restorative Justice is a perfectly viable alternative to the retributive model currently applied in Brazil, and is even compatible with the legal system. Some Brazilian states have used restorative practices to resolve conflicts of small and medium offensive potential, presenting as expressive results of this method the extrication, when allowed by law, the greater re-socialization of individuals, reducing the cases in which they return to delinquency, as well as reducing violence, especially within prisons. The proposal is to think about the future and the restoration of relationships, and not only to focus on the past, on guilt and on reciprocating the harm caused, building a more just and human social body.
\end{abstract}

Keywords: Inefficiency of the prison system. Incarceration culture. Restorative Justice. Resocialization. Social pacification.

\title{
INTRODUÇÃO
}

A Justiça Criminal tem como objetivo principal zelar pelo convívio pacífico entre os membros da sociedade e, por isso, o Estado detém o poder punitivo. Todavia, a utilização extrema e irracional da prisão como principal, senão único, instrumento utilizado pelo Estado para exercer o ius puniendi, além de não cumprir com a finalidade da pena, fere de forma irreparável os direitos e garantias dos seres humanos. Nas palavras de Aury Lopes Júnior: "A ideia de que a repressão total vai sanar o problema é totalmente ideológica e mistificadora. Sacrificam-se direitos fundamentais em nome da incompetência estatal em resolver os problemas que realmente geram a violência ${ }^{4}$.

\footnotetext{
${ }^{4}$ LOPES JUNIOR, Aury. Introdução crítica ao processo penal: fundamentos da instrumentalidade constitucional. Rio de Janeiro: Lumen Juris, 2006. p. 16.
} 
O atual sistema punitivo brasileiro está em crise e deteriorado, com presídios superlotados, que não oferecem o mínimo de condições para atender às necessidades dos presos, bem como cumprir com a função social de ressocializar e reintegrar o indivíduo na sociedade. Várias alternativas ao encarceramento foram propostas e implementadas, com intuito de reduzir e/ou conter a punição extrema, como as penas e medidas alternativas introduzidas pela Lei $n^{\circ} 9.099 / 1995$. Todavia, tais alternativas somente aumentaram o campo de atuação do direito penal e revelaram a verdadeira intenção ou tentativa de remendar o paradigma punitivo.

Diante dessa perspectiva, surge a Justiça Restaurativa, que consiste em um paradigma não punitivo e tem como principal objetivo a reparação dos danos causados às partes envolvidas - vítima, ofensor e comunidade - e, quando possível, a reconstrução das relações rompidas. Apresenta-se como uma alternativa ao modelo retributivo atualmente aplicado no Brasil, tendo em vista a clemência por mudanças mais profundas e concretas diante das ineficiências do sistema penal.

Utilizando-se dos métodos de pesquisa descritivo e explicativo, bem como fundamentada nos estudos teóricos do escritor Howard Zehr, a presente pesquisa visa analisar como as práticas restaurativas reduziriam a cultura de encarceramento em massa, para assegurar os princípios constitucionais da dignidade da pessoa humana, do acesso à Justiça e do exercício da cidadania, possibilitando, assim, a reintegração dos indivíduos de maneira eficaz e permanente na sociedade e, por conseguinte, o desenvolvimento de um corpo social mais justo e humano, que zela pela integridade de seus compatriotas e pela harmonização social.

\section{2 \\ JUSTIÇA RETRIBUTIVA E A POPULAÇÃO CARCÉRÁRIA}

Em todas as épocas, o aprisionamento foi a principal forma de lidar com os intransigentes e controvertidos, mas foi a partir do século XIX que a pena privativa de liberdade se tornou o principal e mais adequado meio coercitivo, já que antes disso as penas corporais eram muito valorizadas como forma de punição, servindo as prisões somente como local provisório para posterior condenação.

À vista disso, o Brasil adotou o sistema retributivo de justiça como forma de resolução dos conflitos criminais, o qual se preocupa 
demasiadamente com a figura do agressor, com qual regra jurídica foi violada ou qual sanção penal deve ser aplicada, além de transferir exclusivamente para o Estado o dever-poder de punir quem cometeu um crime. É um sistema vingativo-punitivo, pois, uma vez que se preocupa tão somente em retribuir o mal causado, faz com que a pena se torne uma maneira de não deixar o indivíduo impune aos olhos da sociedade.

Nesse contexto a figura da vítima é deixada de lado, sobretudo, porque a pena imposta ao criminoso raramente leva em consideração seus interesses, estando mais concentrada em penalizar, em servir como exemplo de autoridade do Estado, do que de alento à vítima. Por esse motivo, a justiça retributiva dificilmente consegue restaurar a condição jurídica da vítima ao status quo anterior à infração, tampouco proporciona a ressocialização do réu - função primordial do direito penal. Pelo contrário: causam inúmeros efeitos negativos à pessoa do preso, contribuindo para a permanência deste no mundo do crime.

Dessa forma, pode-se afirmar que o modelo retributivo de justiça e, por conseguinte, o encarceramento, não surtiram os efeitos desejados. Os dados do Levantamento Nacional de Informações Penitenciárias (Infopen - Atualização Junho/2017), realizado pelo Departamento Penitenciário Nacional (Depen) em parceria com o Ministério Público da Justiça e Segurança Pública, apontam que a população prisional brasileira ultrapassou a marca de 726 mil pessoas privadas de liberdade, o que representa um aumento da ordem de $707 \%$ em relação ao total registrado no início da década de 90 , passando a ter a terceira maior população prisional do mundo ${ }^{5}$.

Em relação ao número de vagas, observa-se um déficit total de 303.112 mil vagas e uma taxa de ocupação média de $171,62 \%$ em todo o país (tabela 1). O relatório consta ainda que mais de $80 \%$ da população prisional encontra-se em unidades com déficit de vagas, independente do regime de cumprimento da pena, e que mais de $70 \%$ dos estabelecimentos penais comportam mais presos do que o número de vagas disponíveis ${ }^{6}$. Essas taxas de ocupação revelam que tanto as pessoas privadas de liberdade quanto os servidores e colaboradores que ocupam os espaços das prisões vivem em condições insalubres.

\footnotetext{
${ }^{5}$ MOURA, Marcos Vinícius (org). Levantamento Nacional de Informações Penitenciárias: atualização Junho/2017. Brasília: Ministério Público da Justiça e Segurança Pública, Departamento Penitenciário Nacional. 2019. p 7-9.

${ }^{6}$ Idem. Ibidem. p 7.
} 


\section{Brasil - Junho de 2017}

Total da população prisional

726.354

Sistema Penitenciário

706.619

Secretarias de Segurança e Carceragens*

19.735

Total de Vagas

423.242

Déficit de vagas

303.112

Taxa de Ocupação

$171,62 \%$

Taxa de Aprisionamento

349,78

Tabela 1. Pessoas privadas de liberdade no Brasil em junho de $2017^{78}$

Quais seriam, no entanto, as motivações dessa deterioração do sistema prisional brasileiro? Diversos fatores, que não se resumem apenas ao aumento da criminalidade, colaboram para que essa crise se perpetue. A presente pesquisa, contudo, se concentra em analisar quatro principais razões, tais como a sanção da nova lei de drogas, o excesso das prisões provisórias, o uso de regime fechado mesmo quando há penas alternativas e as falhas na ressocialização dos detentos. Ressalta-se que referidos fatores não explicam totalmente o problema, posto que não são os únicos que levaram à crise atual.

\subsection{EFEITOS DA LEI ANTIDROGAS}

Aproximadamente $30 \%$ das incidências penais pelas quais as pessoas privadas de liberdade foram condenadas ou aguardavam julgamento em Junho de 2017 corresponde ao crime de tráfico de drogas, de acordo com o relatório Infopen Junho/2017. À vista disso, acredita-se que um dos efeitos da Lei $\mathrm{n}^{\circ} 11.343 / 06$, popularmente denominada Lei Antidrogas, foi justamente o encarceramento, já que antes dela o índice de

\footnotetext{
${ }^{7}$ Nota: Para o cálculo da população prisional, foram desconsideradas as pessoas em prisão albergue domiciliar, por não se encontrarem em estabelecimentos penais diretamente administrados pelo Poder Executivo.

${ }^{8}$ Levantamento Nacional de Informações Penitenciárias - Infopen, Junho /2017; IBGE, 2017.
} 
pessoas apenadas por crimes relacionados ao tráfico era de apenas $14 \%^{9}$, número consideravelmente inferior aos atuais.

Essa dinâmica de aprisionamento contraria a expectativa gerada pela promulgação da referida legislação, pois se esperava que a distinção entre usuários e traficantes diminuiria a pressão no sistema penitenciário, uma vez que a lei estabelece condenação a penas leves, como, por exemplo, advertência, prestação de serviços comunitários ou medidas educativas para os usuários. O que ocasionou, então, o crescimento de prisões por tráfico de entorpecentes?

Entre os principais motivos do aumento dos números está a falha em diferenciar o usuário de drogas do traficante, posto que os termos da lei atual são subjetivos e, na prática, o juiz é quem decide quem deve ser enquadrado em cada categoria. Como bem explica Cristiano Maronna ${ }^{10}$ :

O Artigo 33 que trata do tráfico coloca como uma das condutas
punidas a cessão gratuita de drogas de uma pessoa a outra. Isso não
é tráfico, o tráfico envolve lucro. Outra coisa é que não se exige
prova. A pessoa flagrada com determinada quantidade é presumida
como traficante. Isso é inaceitável, porque o que se espera é que o
Estado prove que aquela pessoa, de fato, trafica drogas, por meio,
por exemplo, do extrato bancário ou por meio de uma investigação,
com testemunhas etc. Nada disso é exigido, como regra, para uma
pessoa ser condenada por tráfico ${ }^{11}$.

Assim sendo, pode-se considerar que muitas pessoas são presas com pequena quantidade de drogas, baseadas apenas no relato do policial e sem respaldo de um advogado no momento da prisão, situação bastante desfavorável ao acusado. Essas circunstâncias fazem com que aumente a suspeita de que muitos dos traficantes que lotam as cadeias brasileiras seriam, na verdade, apenas usuários de drogas.

\footnotetext{
${ }^{9}$ MARTINS, Helena. Lei de drogas tem impulsionado encarceramento no Brasil.2018. Disponível em: http://agenciabrasil.ebc.com.br/geral/noticia/2018-06/lei-de-drogas-tem-impulsionadoencarceramento-no-brasil. Acesso em: 15 nov. 2018.

${ }^{10}$ Nota: Cristiano Maronna é advogado criminalista e secretário executivo do Instituto Brasileiro de Ciências Criminais e presidente da Plataforma Brasileira de Política de Drogas.

${ }^{11}$ MARONNA, Cristiano. Lei de drogas tem impulsionado encarceramento no Brasil. [Entrevista cedida a] Agência Brasil, Brasília, 24. Jun. 2018. Disponível em: http://agenciabrasil.ebc.com.br/geral/noticia/2018-06/lei-de-drogas-tem-impulsionadoencarceramento-no-brasil. Acesso em: 15 nov. 2018.
} 


\subsection{EXCESSO DA PRISÃO PROVISÓRIA}

O relatório do Infopen Junho/2017 indica que 33,29\% das pessoas presas no Brasil em Junho de 2017 ainda não haviam sido julgadas e condenadas ${ }^{12}$. O Instituto de Defesa de Direito de Defesa (IDDD), em Abril de 2016, na cidade de São Paulo, constatou que 94,8\% das prisões em flagrante são convertidas em previsão preventiva na fase de inquérito policial, sendo que, nas poucas situações em que foi concedida liberdade provisória, em apenas $1 \%$ não houve imposição de medida cautelar alternativa, ou seja, em $4,2 \%$ das vezes a referida liberdade foi condicionada ao cumprimento de medida cautelar ${ }^{13}$.

Nota-se, portanto, que a prisão provisória há tempos vem sendo usada como regra, tornando-se uma forma de antecipação de pena, o que vai totalmente contra a legislação nacional, a qual prevê a excepcionalidade da prisão cautelar, tendo em vista o princípio constitucional da presunção de inocência.

\section{ALTERNATIVAS}

Além do grande número de prisões provisórias no Brasil, existe também o problema das condenações a regime fechado sem necessidade. Mesmo após 20 anos da promulgação da Lei $n^{\circ}$ 9.714/98, que acrescentou artigos ao Código Penal e aprovou a substituição de penas restritivas de liberdade por penas restritivas de direitos em determinados casos, observase que a determinação não foi suficiente para diminuir a população das penitenciárias brasileiras.

Um dos principais motivos para esse insucesso é a grande resistência por parte dos juízes em se utilizarem de penas alternativas para as situações recomendadas, visto que, se as penas alternativas fossem mais

\footnotetext{
12 MOURA, Marcos Vinícius (org). Levantamento Nacional de Informações Penitenciárias: atualização Junho 2017. Brasília: Ministério Público da Justiça e Segurança Pública, Departamento Penitenciário Nacional. 2019. p 14.

13 SILVA, Vivian Peres da; SILVA, Bárbara Correia Florêncio; FERREIRA, Marina Lima; LAGATTA, Pedro. Liberdade em foco: Redução do uso abusivo da prisão provisória na cidade de São Paulo. São Paulo: 2016. p 45. Disponível em: http://www.iddd.org.br/wpcontent/uploads/2016/05/RELATORIO-LIBERDADE-EM-FOCO.pdf. Acesso em: 10 jan. 2018.
} 
aplicadas nos casos de tráfico, por exemplo - principal causa de encarceramento do País -, seria possível reduzir significativamente a população carcerária, uma vez que o pequeno traficante seria enquadrado nas sanções criminais alternativas, quando do cometimento de crime sem violência, e somente o grande traficante seria preso.

No entanto, a falta de controle efetivo das penas alternativas desde o início de sua aplicação faz com que não haja uma real fiscalização de seu cumprimento, sendo este um dos principais motivos de desestímulo e receio por parte dos juízes, que optam por enviar mais pessoas às prisões superlotadas do que aplicar penas alternativas e contribuir para uma possível impunidade.

Dessa forma, por um lado temos a resistência para aplicação das penas alternativas por parte dos juízes, um cenário muito prejudicial ao sistema penitenciário, pois, logicamente, quanto menor o número de pessoas cumprindo pena em regime fechado, menor é a quantidade de detentos nas celas brasileiras e, consequentemente, menor é o risco de caos no sistema. Por outro lado, todavia, a falta de infraestrutura adequada claramente dificulta a aplicação das penas alternativas, uma vez que mencionada ausência de fiscalização pode levar à impunidade do infrator, algo que vai totalmente contra a finalidade da pena e ao interesse público.

\subsection{FALHAS NA RESSOCIALIZAÇÃO E CONSEQUENTE FORTALECIMENTO DO CRIME}

Ressocializar é dar ao condenado o suporte necessário para reintegrá-lo na sociedade, é dar a chance de mudar e ter um futuro melhor independente do que ocorreu no passado. As penitenciárias nacionais, porém, seguiram um caminho muito diferente do esperado, oferecendo ambientes precários, superlotados, carentes de recursos e de políticas públicas eficazes para sua manutenção, que causam inúmeros efeitos negativos nos detentos, contribuindo para a permanência deste no mundo do crime.

A não ressocialização dos presos é consequência direta das falhas de um sistema prisional falido que traz como resultado o grande índice de reincidência criminal. Todavia, a sociedade como um todo também é responsável por essa ineficiência, uma vez que contribui para a 
marginalização social desse segmento, se pondo omissa, e por vezes contrária, quanto à política de ressocialização. Melhorias que visam ao desencarceramento e diminuição do caos nas cadeias são vistas pela maioria da população como forma de beneficiar bandidos e, portanto, deixam de estar entre as propostas de governo dos candidatos, levando à omissão ainda maior do Estado.

Assim, na medida em que os presos não são reintegrados corretamente na sociedade, sofrendo com a negligência do Estado e o abandono da população, a probabilidade de permanecerem, e crescerem, no mundo do crime ou reincidirem é muito maior, intensificando a crise do sistema prisional brasileiro. Isso demonstra contrariedade não só com a legislação vigente, que estimula a política criminal de ressocialização e desencarceramento, mas também com o direito social à segurança da sociedade - que sofre com a violência - e do preso, tal como do egresso que perdem o direito de assistência prevista no art. 11 da Lei de Execuções Penais (LEP) ${ }^{14}$, cujo objetivo é justamente prevenir o crime e orientar o retorno à convivência em sociedade.

\section{JUSTIÇA RESTAURATIVA}

Após o reconhecimento da crise de legitimidade e eficiência do sistema, várias alternativas ao encarceramento foram propostas $\mathrm{e}$ implementadas, com intuito de reduzir e/ou conter a punição extrema, tais como as penas e medidas alternativas introduzidas pela Lei 9.099/1995. Todavia, tais alternativas somente aumentaram o campo de atuação do direito penal e revelaram a verdadeira intenção ou tentativa de remendar o paradigma punitivo. Nas palavras de Zehr:

A busca de alternativas à privação de liberdade representa uma
outra tentativa de remendar o paradigma. Ao invés de procurar
alternativas à pena, o movimento em prol de alternativas oferece
penas alternativas. Criando novas formas de punição menos
dispendiosas e mais atraentes que a prisão, seus proponentes
conseguem manter o paradigma em pé. Contudo, pelo fato de
constituírem apenas outro epiciclo, não questiona os pressupostos
que repousam no fundamento da punição. E por isso não tem

${ }^{14}$ Art. 11. A assistência será: I - material; II - à saúde; III -jurídica; IV - educacional; V - social; VI religiosa. 
impacto sobre o problema em si - a superlotação carcerária -, problema para o qual pretendiam ser a solução ${ }^{15}$.

Por esses motivos, acredita-se não ser possível alterar a realidade do sistema penal dentro de um paradigma ${ }^{16}$ tão somente punitivoretributivo, no qual, pela própria natureza dos meios existentes (essencialmente a pena), terminará sempre prevalecendo a resposta da força. Por essa razão é que se faz necessário reduzir o exercício do poder punitivo do sistema penal e substituí-lo por alternativas eficientes de solução dos conflitos, construindo novo paradigma.

Foi a partir do reconhecimento das falhas do atual sistema punitivo que passaram a pensar não só na possibilidade de melhorar o seu mau funcionamento, mas também de modificar radicalmente a noção de Justiça Criminal. Surge, então, o conceito de Justiça Restaurativa, um modelo alternativo de resolução de conflitos com conteúdo diverso do jus puniendi. É um paradigma contraste ao sistema retributivo, uma vez que sua proposta é pensar no futuro e na restauração dos relacionamentos, e não somente concentrar-se no passado e na culpa. A justiça convencional afirma: você fez isso e deve ser castigado! A justiça restaurativa indaga: o que pode ser feito agora para restaurar isso?

Há dois pontos cruciais nessa proposta: responsabilizar o ofensor e buscar pela reparação dos danos causados à vítima. Assim sendo, a justiça restaurativa estabelece um conjunto estruturado e sistêmico de princípios, técnicas e ações por meio dos quais os conflitos são solucionados de modo organizado, com a participação da vítima, ofensor, famílias e comunidade, bem como de um terceiro imparcial que intervirá no sentido de alcançar o resultado restaurativo, ou seja, um pacto que deixe de lado os interesses individuais das partes e promova a reintegração social entre o ofensor e o ofendido.

Ademais, a mudança de paradigma criminal sugerida pelo sistema restaurativo pode ser vista como um movimento a procura do sentido amplo de acesso à justiça - um dos elementos essenciais do Estado Democrático de Direito - uma vez que viabiliza tanto o acesso formal ao judiciário - por meio de acordos restaurativos proporcionais ao delito cometido, ratificados pelo Estado -, quanto o acesso material à ordem

\footnotetext{
15 ZEHR, Howard. Trocando as lentes: um novo foco sobre o crime e a justiça. São Paulo: Palas Athena, 2008. p. 90.

${ }^{16}$ Nota: Segundo Zehr (2008), entende-se como paradigma o modo específico de construir a realidade, de compreender os fenômenos e o mundo. Conforme o autor, os paradigmas moldam a forma como definimos problemas e o nosso reconhecimento do que sejam soluções apropriadas.
} 
jurídica considerada justa - pela disponibilização de vias mais satisfatórias de resolução de conflitos aos sujeitos e comunidades cercados pelo conflito.

A justiça restaurativa, portanto, baseia-se em um paradigma não punitivo, que aponta soluções às ineficácias do sistema retributivo atual, modificando o foco do processo penal na determinação da culpa e da punição para a transgressão criminal. Conforme expõe Brancher, esse modelo de justiça delineia uma nova abordagem sobre a questão do crime e das infrações, possibilitando um referencial paradigmático na humanização e pacificação das relações sociais envolvidas num conflito ${ }^{17}$.

\subsection{DAS PRÁTICAS RESTAURATIVAS}

A busca por reconciliação entre vítima e agressor é uma conduta que tem sido aplicada com sucesso em vários países do mundo. $\mathrm{O}$ movimento internacional de reconhecimento e incremento de métodos restaurativos teve início no final da década de setenta e início da década de oitenta, no Canadá e na Nova Zelândia, sendo este o primeiro País a positivar em seu ordenamento jurídico a Justiça Restaurativa, em 1989.

A experiência neozelandesa teve tanto êxito em questão de prevenção, reincidência, reparação de danos e resolução de conflitos que, em 2002, as práticas restaurativas tornaram-se opcionais ao sistema de Justiça Criminal tradicional. Esta iniciativa serviu de inspiração para vários outros Países (Austrália, Canadá, Estados Unidos, África do Sul, Argentina, Colômbia, dentre outros países), o que fez com a Justiça Restaurativa fosse amplamente discutida mundo afora, o que resultou na edição da resolução $n^{\circ}$ 2002/12 pelo Conselho Econômico e Social da ONU.

No Brasil os primeiros estudos teóricos e análise da atividade judiciária sob o prisma restaurativo ocorreu em 1999, por conta do Prof. Pedro Scuro Neto, no Rio Grande do Sul. Com a criação da Secretaria da Reforma do Judiciário, órgão do Ministério da Justiça, em 2003, o tema ganhou expressão nacional e, com intuito de ampliar o acesso dos cidadãos à justiça e diminuir a morosidade dos processos, referida entidade firmou

17 BRANCHER, Leoberto Narciso. Justiça restaurativa: a cultura da paz na prática da Justiça. Disponível em: http://jij.tjrs.jus.br/doc/justica-restaurativa/A-Cultura-de-Paz-na-Pratica-daJustica.pdf. Acesso em: 8 mai. 2018. 
acordo de cooperação técnica com o Programa das Nações Unidas para o Desenvolvimento - PNUD, decisão que gerou o Programa de Modernização da Gestão do Sistema Judiciário.

No final de 2004 e início de 2005, o PNUD concedeu um apoio financeiro que possibilitou a criação de três projetos pilotos sobre justiça restaurativa, quais sejam: o de Brasília - DF, no Juizado Especial Criminal; o de Porto Alegre - RS, dirigido para a justiça da infância e juventude, chamado Justiça do Século XXI; e o de São Caetano do Sul - SP, voltado também para o campo da infância e juventude.

Dos projetos pilotos mencionados acima, o projeto Justiça Restaurativa para o Século XXI, do Rio Grande do Sul, é a ação mais consolidada de Justiça Restaurativa no Brasil, sendo, inclusive, polo de treinamento para estudiosos de todo o País que pretendem repetir os métodos em seus Estados, juntamente ao Sistema de Justiça da Infância e Juventude, a escolas, ONGs, instituições de atendimento à infância e juventude e comunidades.

Com resultados tão satisfatórios, outros Estados brasileiros aderiram ao movimento restaurativo. Em 2011, por exemplo, o Tribunal de Justiça do Estado de Minas Gerais, com a publicação da Portaria Conjunta n 221/2011, oficializou o projeto "Justiça Restaurativa" na Comarca de Belo Horizonte - Minas Gerais. O Estado do Maranhão também desenvolveu um projeto de Justiça Restaurativa, no município de São José de Ribamar. Com início no ano de 2009, a iniciativa tem como foco a resolução de conflito juvenil, tanto no âmbito do Poder Judiciário quanto fora dele, neste caso, por meio das escolas e do Núcleo de Justiça Juvenil Restaurativa, construído na periferia da cidade.

O ponto comum de todas as experiências, não só brasileiras, mas também internacionais, revelam a justiça restaurativa com um sistema que transmite a sensação de dignidade, igualdade e de verdadeira justiça aos envolvidos, fazendo com que atingidos estejam mais satisfeitos, tranquilos e seguros com o resultado, motivo pelo qual os processos circulares têm crescido tanto nos locais em que estão sendo desenvolvidos.

\section{CONSIDERAÇÕES FINAIS}

Diante da precária situação da população carcerária brasileira, que é a terceira maior do mundo em termos absolutos, e da ineficiência do 
sistema prisional na ressocialização e recuperação dos indivíduos envolvidos num crime, discutir penas e sanções alternativas para os que não praticaram crime grave e violento, bem como buscar formas de resolução de conflitos que assegurem a promoção dos direitos humanos e a inclusão na sociedade, são medidas essenciais para que as injustiças, as carnificinas e toda a desumanidade associada à realidade das prisões nacionais não se perpetue.

A implementação da Justiça Restaurativa no Brasil simboliza, portanto, a oportunidade de um sistema criminal democrático, que alcance real transformação dos envolvidos, possibilitando a ascensão da cidadania, da inclusão e da paz social com dignidade, além do acesso ao judiciário e à uma ordem jurídica justa. Ademais, considerando as mais variadas formas de heterocomposição (jurisdição, mediação, conciliação e arbitragem), o procedimento restaurativo traz soluções mais abrangentes e direcionadas para cada tipo de conflito, não se limitando, como visto, a resolver delitos de menor potencial ofensivo, juvenis e escolares.

A proposta é pensar no futuro e na restauração dos relacionamentos, e não somente concentrar-se no passado e na culpa. Um futuro que se baseia em um paradigma não punitivo, que aponta soluções às ineficácias do sistema retributivo atual, modificando o foco do processo penal na determinação da culpa e da punição para a transgressão criminal.

Entretanto, ainda existem grandes obstáculos e preconceitos jurídicos que prejudicam uma maior aplicação e desenvolvimento da Justiça Restaurativa no Brasil, sendo extremamente necessário "mudar aquela velha opinião formada sobre tudo", desmistificar a punição e promover o entendimento das práticas restaurativas como alternativa à crise penitenciária. Afinal, não aprisionar, neste caso, não significa impunidade, mas sim que existem mecanismos mais eficientes, baratos e adequados para responsabilizar o transgressor.

Por fim, nos resta refletir no sentido de que a política de encarceramento não é produto do Estado Democrático de Direito, posto que contraria a ideia de um Estado de Direito Universal. Superlotar as prisões de jovens, na maior parte das vezes pobres, que não representam perigo real para a sociedade, além de não ser efetivo para a redução da criminalidade, fatalmente produzirá ainda mais conflitos, injustiça e violência. 


\section{REFERÊNCIAS BIBLIOGRÁFICAS}

BITENCOURT, Cezar Roberto. Falência da Pena de Prisão: Causas e Alternativas. 4. ed . São Paulo: Saraiva, 2011.

BLUME, Bruno André. 4 causas para a crise do sistema prisional brasileiro. 2017. Disponível em: <https://www.politize.com.br/crise-do-sistema-prisional-brasileirocausas/>. Acesso em: 12 nov. 2018.

BRANCHER, Leoberto Narciso. Justiça restaurativa: a cultura da paz na prática da Justiça. Disponível em: http://jij.tjrs.jus.br/doc/justica-restaurativa/A-Cultura-de-Paz-naPratica-da-Justica.pdf. Acesso em: 8 mai. 2018

BRASIL. Lei no 9.714, de 25 de novembro de 1998. . Brasília, Disponível em: <http://www.planalto.gov.br/ccivil_03/LEIS/L9714.htm>. Acesso em: 25 jul. 2019.

BRASIL. Resolução n 225, de 31 de maio de 2016. . Brasília, Disponível em: < http://www.cnj.jus.br/atos-normativos?documento=2289>. Acesso em: 12 ago. 2018.

CARVALHO, Salo de. Memória e esquecimento nas práticas punitivas: criminologia e sistemas jurídico-penais contemporâneos. Porto Alegre: EDIPUCRS, 2008.

GRECO, Rogério. Direitos humanos, sistema prisional e alternativas à privação de liberdade. São Paulo: Saraiva, 2013.

LARA, Caio Augusto Souza; ORSINI, Adriana Goulart de Sena. Dez anos de práticas restaurativa no Brasil: A afirmação da Justiça Restaurativa como política pública de resolução de conflitos e acesso à justiça. Responsabilidades, Belo Horizonte, v. 2, n. 2, p.305-324, set. 2012.

LOPES JUNIOR, Aury. Introdução crítica ao processo penal: fundamentos da instrumentalidade constitucional. Rio de Janeiro: Lumen Juris, 2006.

MARONNA, Cristiano. Lei de drogas tem impulsionado encarceramento no Brasil. [Entrevista cedida a] Agência Brasil, Brasília, 24. Jun. 2018. Disponível em: http://agenciabrasil.ebc.com.br/geral/noticia/2018-06/lei-de-drogas-tem-impulsionadoencarceramento-no-brasil. Acesso em: 15 nov. 2018.

MARTINS, Helena. Lei de drogas tem impulsionado encarceramento no Brasil.2018. Disponível em: http://agenciabrasil.ebc.com.br/geral/noticia/2018-06/lei-de-drogas-temimpulsionado-encarceramento-no-brasil. Acesso em: 15 nov. 2018.

MELO, Marcos Luiz Alves de. A carência de políticas públicas de ressocialização no sistema carcerário brasileiro.2018. Disponível em:

<http://www.justificando.com/2018/06/08/a-carencia-de-politicas-publicas-deressocializacao-no-sistema-carcerario-brasileiro/>. Acesso em: 15 nov. 2018. 
MOURA, Marcos Vinícius (org). Levantamento Nacional de Informações Penitenciárias: atualização Junho/2017. Brasília: Ministério Público da Justiça e Segurança Pública, Departamento Penitenciário Nacional. 2019.

OLIVEIRA, Antônio Cláudio Mariz de. Questão penitenciária: Uma questão social. 2005. Disponível em: <https://www1.folha.uol.com.br/fsp/opiniao/fz0606200509.htm>. Acesso em: 22 jul. 2019.

SICA, Leonardo. Justiça restaurativa e mediação penal: o novo modelo de justiça criminal e de gestão de crime. Rio de Janeiro: Lumen Juris, 2007.

SILVA, Vivian Peres da; SILVA, Bárbara Correia Florêncio; FERREIRA, Marina Lima; LAGATTA, Pedro. Liberdade em foco: Redução do uso abusivo da prisão provisória na cidade de São Paulo. São Paulo: 2016. p 45. Disponível em: http://www.iddd.org.br/wpcontent/uploads/2016/05/RELATORIO-LIBERDADE-EM-FOCO.pdf. Acesso em: 10 jan. 2018.

ZEHR, Howard. Trocando as lentes: um novo foco sobre o crime e a justiça. São Paulo: Palas Athena, 2008. 